\title{
Neonatal Microbiome- can we Interfere?
}

\author{
Tatjana Nikolic* \\ Department of Neonatology, Clinic for Ginecology and Obstetrics Clinical Centre of Serbia,Serbia
}

Submission: February 28, 2018; Published: July 19, 2018

*Corresponding author: Tatjana Nikolic, Department of Neonatology, Clinic for Gynecology and Obstetrics Clinical Centre of Serbia, Višegradska 26, Belgrade, Serbia, Email: tatjana.nikolic.65@gmail.com

\begin{abstract}
There is increasing body of evidence that microbiome is a major factor determining our health. In growing infants, dysbiosis can lead to susceptibility of infections (especially necrotic enterocolitis), colic and general digestive discomfort. Also, dysbiosis is implicated in lifelong health, by increasing the risk of a wide range of diseases and medical conditions including allergy, autoimmune diseases, cardiovascular and metabolic diseases, digestive disorders, even psychological disorders such as autism, anxiety and depression. Early infancy is an important window for establishing host-microbiome interactions. Intestinal colonization is initiated as early as during fetal life and continues during delivery and early infancy. Among the most important factors that influence early colonisation are the mode of delivery and the gestational age of the newborn. During early infancy, there is a range of other very important factors that are implicated in the development of gut microbiome, such as duration of breastfeeding, infections and antibiotic use, as well as several environmental factors (family size, cultural and geographical influences, early exposure to animals). Better understanding of factors dictating early colonization can point out some possibilities to interfere during that critical period and enable wellbeing throughout the entire life.
\end{abstract}

Keywords: Neonate; Microbiome; Dysbiosis; Mammarian glands; Placenta, Amniotic fluid Umbilical cord blood

\section{Introduction}

Microbes, mostly bacteria's, colonize every surface of our body, including the organs that used to be considered sterile such as lungs, placenta and mammarian glands. We have tenfold more bacterial cells in our body than our own, which is over 100trillion microbial cells with 8million genes versus our 22000 genes of all body sites, the gut is the most heavily populated and represents the complex and dynamic microbiome community [1-5].

Microbiome is unique for every person, like a finger print. Within the gut of each individual, a group of about 160 bacterial species can be found from a total of approximately 1000 species of known prevalent bacteria [3-6]. Even, identical twins only share 50 to $80 \%$ of the species in the gut microbiome, despite the fact that host genotype plays an important role in determining the bacterial composition in the gut [7-8]. Due to the influence of environmental factors, the composition of gut microbiome varies within the same individual over time, as well. However, despite these changes in microbial composition and interindividual differences, the entire genome of the gut microorganisms is comparable across the human population $[3,7]$.

\section{Significanse of Neonatal Microbiome}

The term "microbiome", formerly known as "microbiota", was coined by Joshua Lederberg, an American molecular biologist. This Nobel winner argued that microorganisms inhabiting human body should be included as part of the human genome, because of their influence on human physiology [9]. And indeed, the gut microbiome has multiple and very important functions that include nutritional, physiological, metabolic and immunological functions $[3,10]$.

According to that, there is increasing body of evidence that microbiome is a major factor determining our health. The association between gut dysbiosis and the development of various disorders has been recognised a long time ago. Even Hippocrates has been quoted as saying "death sits in the bowels" and "bad digestion is the root of all evil" in 400 B.C. and is becoming well established [11]. In growing infants, dysbiosis can lead to susceptibility of infections (especially necrotic enterocolitis), colic and general digestive discomfort. Also, looks like that dysbiosis is implicated in lifelong health, by increasing the risk of a wide range of diseases and medical conditions including allergy, autoimmune diseases, cardiovascular and metabolic diseases, digestive disorders, even psychological disorders such as autism, anxiety and depression [3,12-14].

\section{Factors affecting Microbiome Composition}

Early infancy is an important window for establishing hostmicrobiome interactions. We should be aware of the fact that intestinal colonization is initiated as early as during fetal life and continues during delivery and early infancy [15]. This period of colonization seems to be crucial for life long health. In addition to host genome, there are several factors that appear to be very 
important for affecting infant gut microbiome composition and include: mother to infant vertical transmission during pregnancy, mode of delivery, gestational age, diet, medication use and environment.

At the end of the 19th century, Henry Tissier, pediatritian at the Paster institute in Paris, asserted that human babies develop within a sterile environment and that they acquire first bacterial inoculum on their way through the birth canal. For more than a century, the sterile womb hypothesis remained dogma. Any bacterial presence in the uterus was assumed to be dangerous for the fetus. To a certain extent, that was true, since a strong correlation between intrauterine infections and preterm labor has been found, especially when birth occurs before 30weeks of pregnancy. The possible explanation would be the influence of maternal immune factors on bacterial invasion of the amniotic cavity and the promotion of inflammatory cascade, which can lead to premature labor. As regards healthy, term pregnancies, relatively few studies have examined their uterine microbiome $[4,16]$.

However, the dogma of sterile fetal life has recently been challenged $[16,17]$. Indeed, the presence of microbe's traces have been found in placenta, amniotic fluid and umbilical cord blood of term infants without any indication of inflammation. Meconium is not sterile either, since it harbors its own microbiome, only less diverse than adults one $(4-5,17,18)$. During pregnancy, future mother's body undergoes many adaptation changes of virtually all organs, affecting in the same time her oral, urinary tract, vaginal and mammal microbiome, resulting in dramatic remodeling and reduction of microbial diversity in the gut $[19,20]$. The study of Jimenez, on mouses, has shown the transfer of maternal gut bacteria to fetus in mammals, but the exact origin, timing, as well as the significance of intrauterine microbe transfer, is still not clear $[17,19]$.

Among the most important factors that influence early colonization are the mode of delivery and the gestational age of the newborn. On their way through the birth canal, virginally born newborns form microbiome similar to mother's vaginal and fecal bacteria composition, in contrast to those born by cesarean section whose microbiome resemble bacteria from mother's skin and hospital environment. In addition, prophylactic antibiotic therapy prior cesarean section, which is standard care and part of the guidelines in many countries, also has important role in altering the microbiome of these infants. We should mention here, that cesarean born babies, among all of these, have delayed and less probability of being breastfed. So, in comparation to virginally born, infants delivered by cesarean section have lower total bacterial count and less diversity of bacteria with higher levels of Staphylococcus, Corynebacterium and low or absent Bifidobacterium. Eventually, these babies "catch-up" the diversity and stability of the microbial composition of vaginal birth babies, but still retain a fact that they had aberrant patterns of colonization during one critical period for immune and metabolic development $[3,13,14,18]$.
There is a significant difference between microbiome of healthy term and premature newborns. Microbiome of preterm infants is characterized by delayed colonization, lower diversity with lower proportion of beneficial Bifidobacteria and increased susceptibility to colonization with pathogenic microbes. In addition to immature gut structure and function, premature infants are under severe risk of delayed and aberrant colonization, taking in consideration factors such as aseptic environment of the intensive care unit, frequent use of total parenteral nutrition with delayed enteral feeding, as well as frequent prenatal and postnatal antibiotic administration $[3,13,18,21]$.

Mode of early nutrition also plays a very important role in gut colonization $[3,13,18]$. By the end of the first week of life, in a gut of healthy term babies predominate beneficial Bifidobacteria and Lactobacillus, while in formula fed infants prevalent flora is more like adult one, with abundance of potentially pathogenic bacteria (18). Human milk is rich in prebiotics and probiotics, both very benefical for the gut. Prebiotics of human milk, soluble, non-digestible carbohydrate molecules, selectively stimulate the growth of gut bacteria, particularly Bifidobacteria, and can bind pathogens, preventing their adhesion to the mucosal surface. They are present in 10 to 100 fold the concentration of oligosaharides found in cow's milk [22]. Also, 2 to 18 species from the total of over 200 different species of bacteria could be isolated from human milk [23]. For the newborn, human milk presents a rich source of beneficial bacteria's that significantly contribute to the composition of healthy gut microbiome $[3,18]$. It is also important to note that the composition of breast milk depends on the health of the mother, her immunologic, metabolic and nutritional status and diet, socioeconomic status, stress, antibiotic use, as well as her own microbiome [5].

After birth, during early infancy, there is a range of other very important factors that are implicated in the development of gut microbiome. In addition to the duration of breastfeeding, infections and antibiotic use, several environmental factors (including family size, cultural and geographical influences, early exposure to animals) significantly contribute to microbiome composing [13,14,24].

There is a strong association between microbiome disturbances and antibiotic use, both prenatally and postnatally. The exact influence of antibiotic treatment is difficult to predict due of the differences in antibiotic specificity, dosage, administration route and length of treatment. However, studies have shown that about one third of bacterial species may be disrupted, without recovery of the microbiome composition within 4weeks and only partial recovery within 8weeks [3,25-27]. Even a course, as short as 48hours, of parenteral use of ampicillin and gentamicin appears to cause significant reduction of Bifidobacterium and Lactobacillus species and allows an overgrowth of other species such as Proteobacteria in term newborn [27]. So, early empiric use of antibiotics can cause sustained suppression of microbial diversity and increase the risk of rebound pathogenic overgrowth. Delayed and disrupted gut colonization can also be the result of 
perinatal antibiotic treatment, especially in premature infants $[3,28]$.

It became clear that the environment, in which newborn and young infant grow, also represents a significant factor influencing microbiome development. Numerous epidemiological studies have shown that children who grow up on traditional farms and had an early-life contact with farm animals are protected from asthma, hay fever and allergic sensitization [24,29-30].

\section{Conclusion}

The influence of the microbiome composition on lifelong health, starting from the very beginning of life, became obvious. This should encourage further research in the field of early colonization and all involved factors. Better understanding of factors dictating early colonization can point out some possibilities to interfere during that critical period and enable wellbeing throughout the entire life.

\section{References}

1. Gerritsen J, Smidt H, Rijkers GT, de Vos WM (2011) Intestinal microbiota in human health and disease: the impact of probiotics. Genes Nutr 6(3): 209-240.

2. Martin R, Nauta AJ, Ben Amor K, Knippels LM, Knol J, et al. (2010) Early life: gut microbiota and immune development in infancy. Benef Microbes 1(4): 367-382.

3. Shamir R, van Elburg, Knol J, Dupont C (2015) Gut Health in Early life: Significance of the Gut Microbiota and Nutrition for Development and Future Health. Essental Knowledge Briefings Wiley, USA, pp. 3-75.

4. Funkhouser LJ, Bordenstein SR (2013) Mom Knows Best: The Universality of Maternal Microbial Transmission. PLoS Biol 11(8): e1001631.

5. Luoto R, Collado MC, Salminen S, Isolauri E (2013) Reshaping the Gut Microbiota at an Early Age: Functional Impact on Obesity Risk? Ann Nutr Metab 63(suppl 2): 17-26.

6. Qin J, Li R, Raes J, Arumugam M, Burgdorf KS, et al. (2010) A human gut microbial gene catalogue established by metagenomic sequencing. Nature 464: 59-65.

7. Parfrey LW, Knight R (2012) Spatial and temporal variability of the human microbiota. Clin Microbiol Infect 18(suppl 4): 8-11.

8. Zoetendal EG, Akkermans ADL, Akkermans-van Vliet WM, de Visser JGM, de Vos WM, et al. (2001) The host genotype affects the bacterial community in the human gastrointestinal tract. Microb Ecol Health Dis 13(3): 129-134.

9. Lederberg J, McCray A (2001) Ome sweet 'omics: -- A genealogical treasury of words. The Scientist 15(7): 8.

10. Rajlic-Stojanovic M, Vos de WM (2014) The first 1000 cultured species of the human gastrointestinal microbiota. FEMS Microbiol Rev 38(5): 996-1047.

11. Sekirov I, Shannon L, Russell L, Finlay BB (2010) Gut microbiota in Health and Disease. Physiol Rew 90(3): 859-904.

12. Kinross JM, Darzi AW, Nicholson JK (2011) Gut microbiome- host interactions in health and disease Genome Med 3(3): 14.
13. Clarke G, O'Mahony SM, Dinan TG, Cryan JF (2014) Priming for health: gut microbiota acquired in early life regulates physiology, brain and behavior. Acta Paediatr 103(8): 812-819.

14. Kumar M, Babaei P, Ji B, Nielsen J (2016) Human gut microbiota and healthy aging: Recent developments and future prospective. Nutr Healthy Aging 4(1): 3-16.

15. Koleva PT, Kim JS, ScottJA, Kozyrskyj AL (2015) Microbial programming of health and disease starts during fetal life. Birth Defects Res C Embryo Today 105(4): 265-277.

16. Romano-Keeler J, Weitkamp JH (2015) Maternal influences on fetal microbial colonization and immune development. Pediatr Res 77(1-2): 189-195.

17. Collado MC, Rautava S, Aakko J, Isolauri E, Salminen S (2016) Human gut colonisation may be initiated in utero by distinct microbial communities in the placenta and amniotic fluid. Sci Rep 6: 23129.

18. Unger S, Stintzi A, Shah P, Mack D3, O'Connor DL (2015) Gut microbiota of the very-low-birth-weight infant. Pediatric Research 2015; 77(1-2): 205-213.

19. Jiménez E, Fernandez L, Marin ML, Martín R, Odriozola JM, et al. (2005) Isolation of commensal bacteria from umbilical cord of healthy neonates born by cesarean section. Curr Microbiol 51(4): 270-274.

20. Cho I, Blaser MJ (2012) The human microbiome: at the interface of health and disease. Nature Reviews Genetics 2012; 13(4): 260-270.

21. Groer MW, Luciano AA, Dishaw LJ, Ashmeade TL, Miller E, et al. (2014) Development of the preterm infant gut microbiome: a research priority. Microbime 2: 38.

22. Georgi G, Bartke N, Wiens F, Stahl B (2013) Functional glycans and glycoconjugates in human milk. Am J Clin Nutr 98(2): 578S-585S.

23. Jeurink PV, van Bergenhenegouwen J, Jimenez E, Knippels LM, Fernández L, et al. (2013) Human milk a source of more life than we imagine. Benef Microbes 4(1): 17-30.

24. Von Mutius E, Vercelli D (2010) Farm living: effects on childhood asthma and allergy. Nat Rev Immunol 10(12): 861-868.

25. Bischoff SC (2011) Gut health: a new objective in medicine? BMC Med 9: 24.

26. Tanaka S, Kobayashi T, Songjinda P, Tateyama A, Tsubouchi M, et al. (2009) Influence of antibiotic exposure in the early postnatal period on the development of intestinal microbiota. FEMS Immunol Med Microbiol 56(1): 80-87.

27. Fouhy F, Guinane CM, Hussey S, Wall R, Ryan CA, et al. (2012) Highthroughput sequencing reveals the incomplete, short-term recovery of infant gut microbiota following parenteral antibiotic treatment with ampicillin and gentamicin. Antimicrob Agents Chemother 56(11): 5811-5820.

28. Arboleya S, Sanchez B, Milani C, Duranti S, Solís G, et al. (2015) Intestinal microbiota development in preterm neonates and effect of perinatal antibiotics. J Pediatr 166(3): 538-544.

29. Gassner-Bachmann M, Wuthrich B (2000) Farmerc children suffer less from hay fever and asthma. Dtch Med Wochenschr 125(31-32): 924931.

30. Wlasiuk G, Vercelli D (2012) The farm effect, or: when, what and how a farming environment protects from asthma and allergic disease. Curr Opin Allergy Clin Immunol 12(5): 461-466. 
This work is licensed under Creative
Commons Attribution 4.0 Licens
DOI: $10.19080 /$ AJPN.2018.07.555760

Your next submission with Juniper Publishers will reach you the below assets

- Quality Editorial service

- Swift Peer Review

- Reprints availability

- E-prints Service

- Manuscript Podcast for convenient understanding

- Global attainment for your research

- Manuscript accessibility in different formats

( Pdf, E-pub, Full Text, Audio)

- Unceasing customer service

Track the below URL for one-step submission

https://juniperpublishers.com/online-submission.php 